تعيين ميزان مشاركت واحدهاى هيدرولوزيك در سيلاب كل حوضة آبريز رودخانه خرسان

نيما توانيور "، محمد افلاطونى و نجمه نظرى

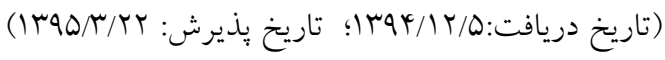

DOI: 10.18869 /acadpub.jstnar.20.78.77

حكيده

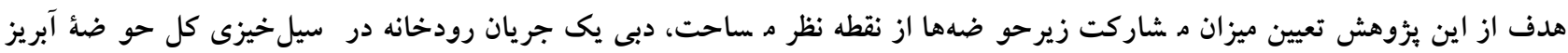

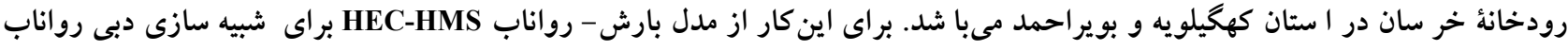

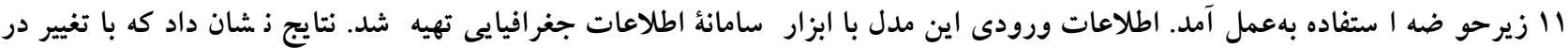

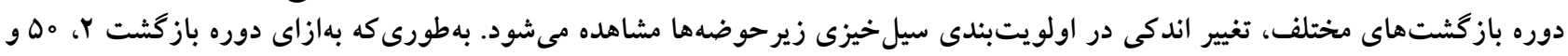

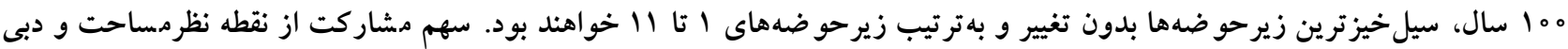

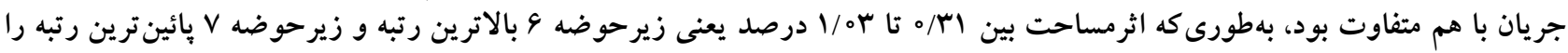

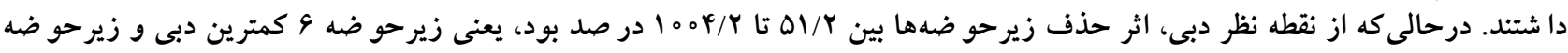

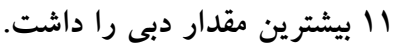

وازههاى كليدى: سيلخيزى، مدل بارش - رواناب، سامانه اطلاعات جغر افيايى، حوضه آبريز، رودخانه خرسان 
رونديابى هيدروليكى سيلاب رودخانهُ مهران رود در منطقة ليقوان

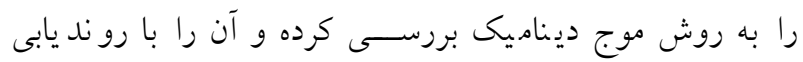
هيدرولوزيكى ماسـكينگام خطى و غيرخطى مورد مقايسـهـ قرار

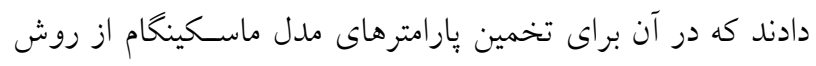

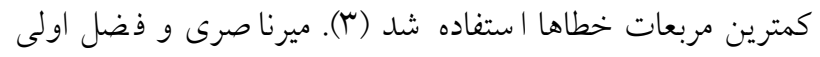

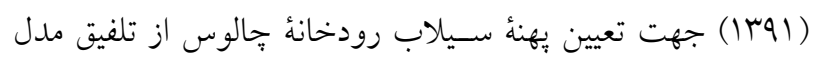

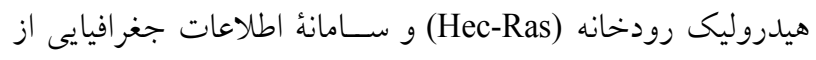

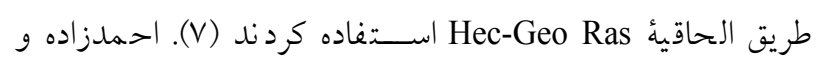

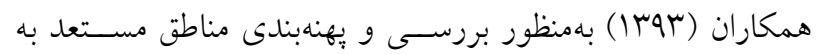

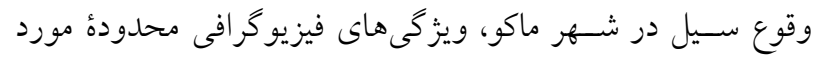

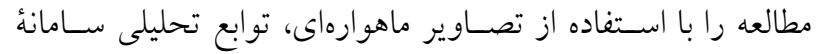

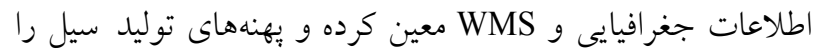
در منطقه، شـناسـيى و مسـيل هاى هدايت كنندة سـيلاب به كالبد

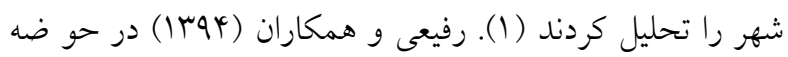

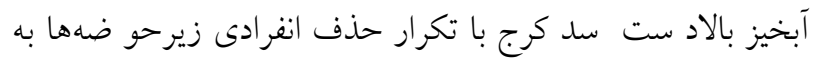

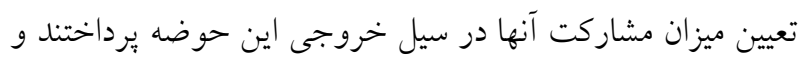

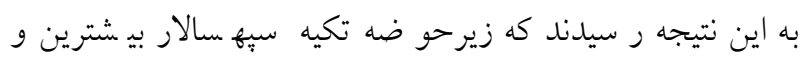

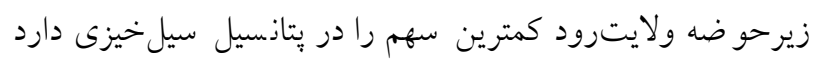

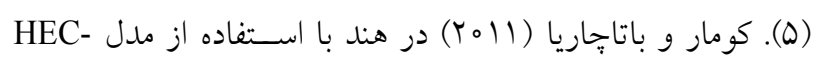

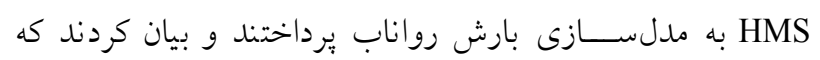

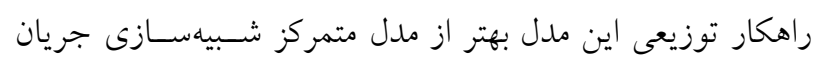

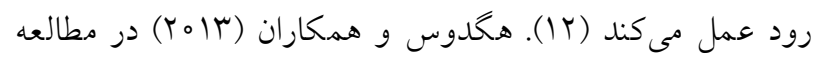

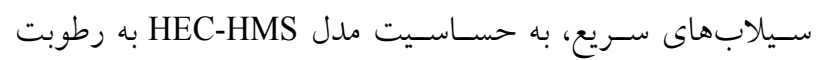

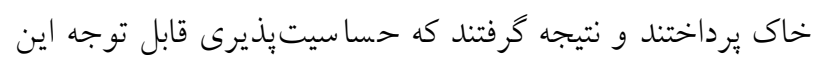

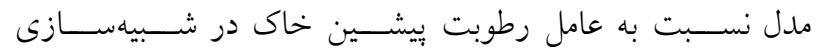

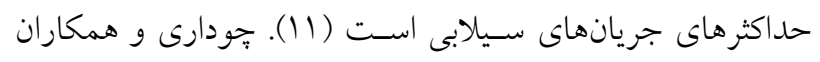

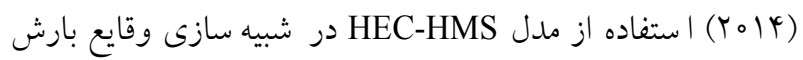
رواناب بهمنظور برآورد حجم رواناب، دبى حداكثر سيل و جريان

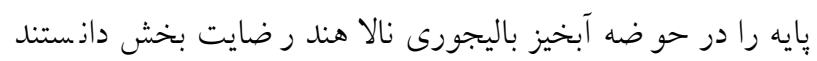

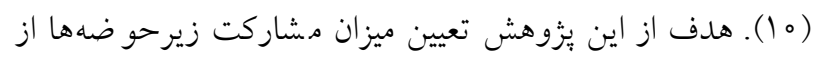
نظر مسـاحت و دبى جريان رودخانه در سـيلخيزى كل حوضـهـ رودخانه خرسان مىباشد.

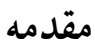

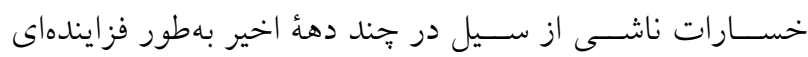

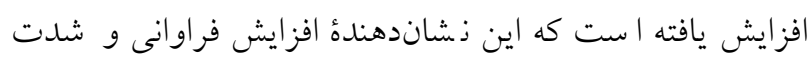

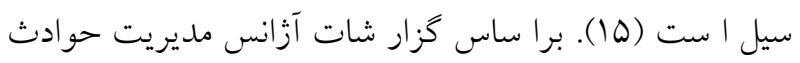

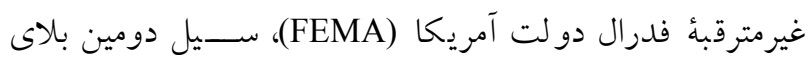

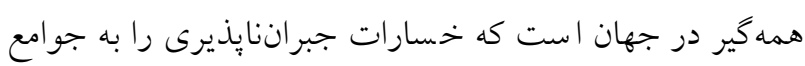

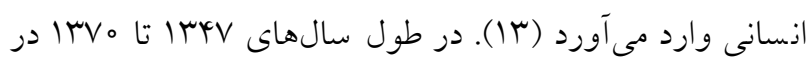

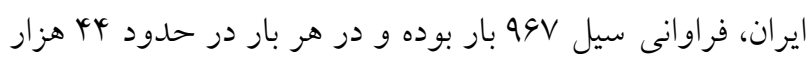

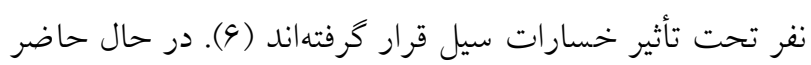

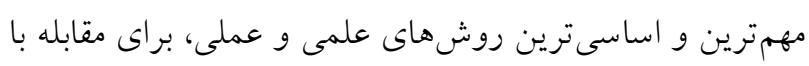

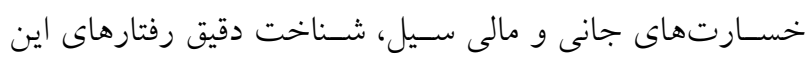

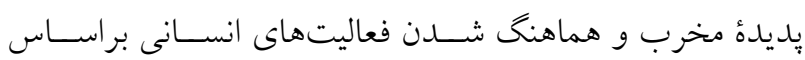

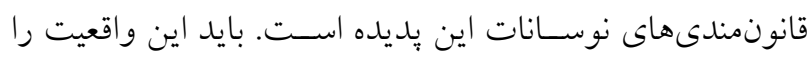

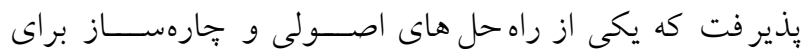

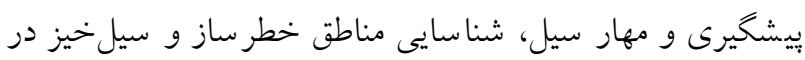
داخل حوضهُ آبريز است. جاو (1909) سيل را يك جريان نسبتاً بالايى از آب مىداند كه آنه بر كانال طبيعى رود، جهت ايجاد رواناب فشـار وارد مى كند (9).

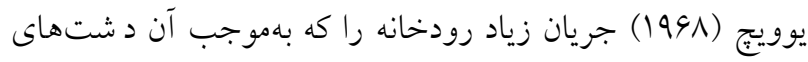

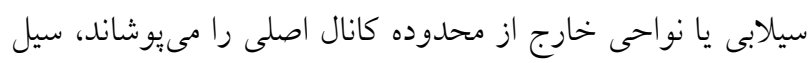

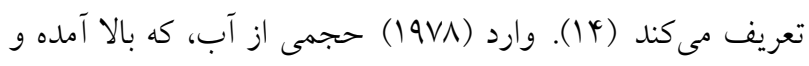

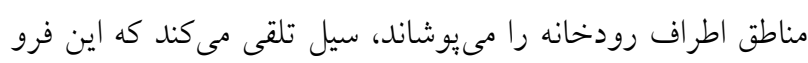

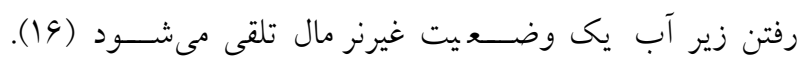

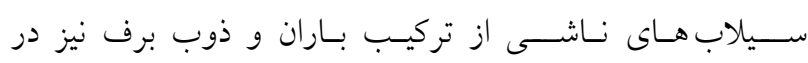

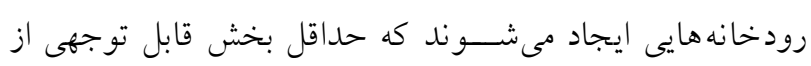

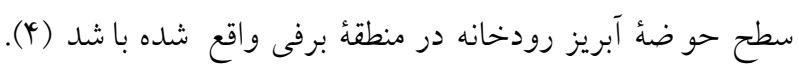

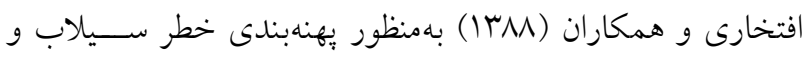
تعيين ضــر يب خطر يذيرى نقاط روســتايى در حريم رودخانه

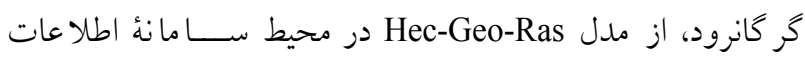

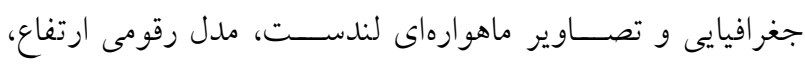

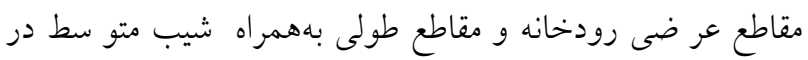

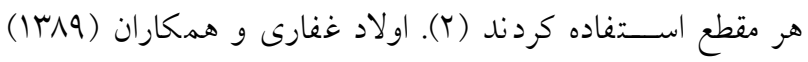




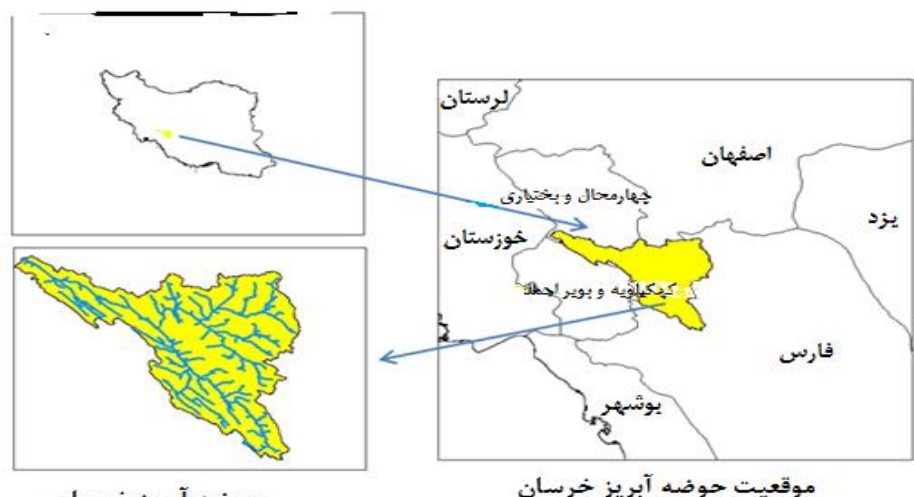

حوضه آبريز خرسان

موقعيت حوضه آبريز خرسان

شكل ا. موقعيت منطقة مورد مطالعه

\begin{tabular}{|c|c|c|c|c|}
\hline ارتفاع (متر) & عرض جغر افيايى & طول جغر افيايى & نام ايستگاه & رديف \\
\hline 1100 & $\mu \circ-\mu_{q}$ & D1- TS & ياسوج & 1 \\
\hline r ro。 & MI-11 & $01-k T$ & حنا & r \\
\hline KOo & $\mu \circ-\Delta V$ & $01-10$ & بِاتاوه & r \\
\hline$M M \circ$ & rוT & $01-0 Y^{4}$ & آلونى & r \\
\hline $10 \Lambda \circ$ & M-M & $0 \circ-Y q$ & لرد كان & 0 \\
\hline GVO & Tr-M & $r q-\Delta r$ & باغ ملك & 9 \\
\hline
\end{tabular}

مختلف آن متغير بوده، بهطورى كه جنوب تا شــمال غرب اقليم نيمه مرطوب معتدل تا نيمه مرطوب سرد، دامنها و نواحى همبار شمال شرق، اقليم نيمه خشى سرد و ارتفاعات فوقانى داراى اقليم مرطوب سرد مىبا شد. يكى ايد ستخاه هيدرومترى (اي ستخاه هيدرومترى بارز) در شمال شرقى كل حو ضه بهعنوان خروجى

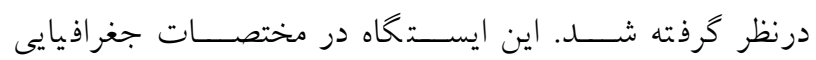
' سז- '0ها تا ' بس- 'اس واقع شده است. سطح حوضهُ آبريز اين

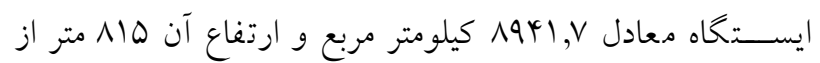
سطح دريا مىبـ- - ـاشد. اين ايستخاه درجهُ يك و مجهز به اشل،

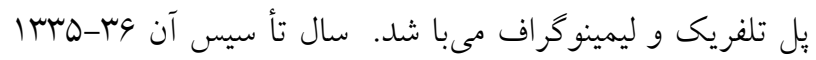
بوده كه تاكنون جمعاً داراى qه سـال آمار مىباشــد. جدول (1) مختصات ايستخاههاى بارانسنجى واقع در داخل و خارج حوضأ آبريز رودخانهُ خرسـان كه در برآورد بارش حوضسهُ آبريز مورد استفاده قرار كرفتهاند را نشان مىدهد (V).

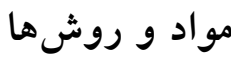

منطقه مورد مطالعه براى انجام اين بززوهش حوضسه آبريز رودخانه خرسـان انتخاب كرديد. شكل ا موقعيت جغر افيايى منطقه مورد مطالعه را ذشان

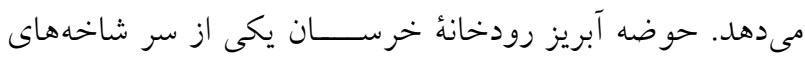
حو ضهُ آبريز رودخانه كارون ا ست. اين زيرحو ضه در ق سمت جنوب غربى كشــور و در نـاحيـهاى بين عرض جغرافيـايى

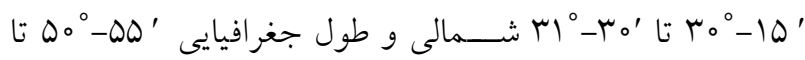

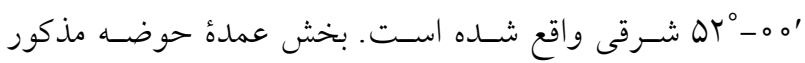

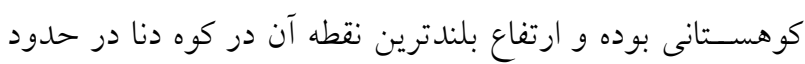

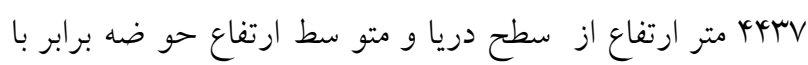
1هبr متر از سطح دريا مىباشد. با توجه به وسعت حوضهُ آبريز و وجود رشــته كوه هاى مرتفع زاگرس، اقليم منطقه در ذقاط 
جدول r. وقايع سيل براى واسنجى و صحت سنجى مدل HMS

\begin{tabular}{|c|c|c|}
\hline دبى اوج سيل (مترمكعب در ثانيه) & تاريخ وقوع سيلاب & ايستخاه آبسنجى \\
\hline $4 \mid Y / T \wedge$ & 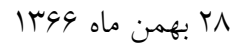 & \multirow{6}{*}{ يستگاه آبسنجى بارز } \\
\hline $9 V / 4$ & rr ITV IN ماه & \\
\hline $10 \circ / 1$ & 9 بهمن ماه ITVA & \\
\hline TI/Q & | 19 بهمن ماه | | | & \\
\hline $1 \circ \wedge r / 9$ & ه دى ماه ץ & \\
\hline$\varphi \circ r / v$ & צr آبان ماه FNk & \\
\hline
\end{tabular}

\section{جداسازى زيرحوضهها} با ا ستفاده از ابزار Arch-Hydro و نق شه رقومى ارتفاعى منطقه، حوضسهُ آبريز خرسـان به ال زيرحوضسه تقسـيم و جداسـازى كرد يد. خروجى اين مدل به عنوان ورودى مدل HEC-Geo

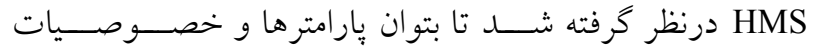
فيزيوكرافى و همجينين شــبكههاى آبر اهلها را وارد مدل - HEC HMS

\section{تعيين دورهاى بازگشت بارش}

براى اينمنظور از توزيع فراوانى مناسب استفاده شد. براى تعيين مناسبترين توزيع فراوانى در ايستخاههاى بارانسنجى با استفاده

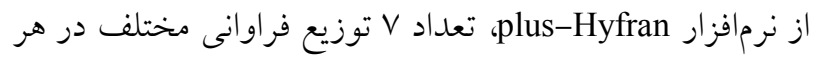
ايستخاه باران سنجى روى حداكثر بارش عب ساعته مورد ارزيابى

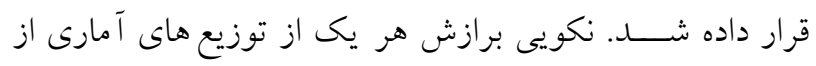

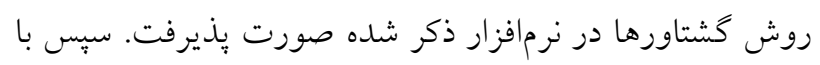
اسـتفاده از بهترين توزيع فراوانى هر ايستخاه، اقدام به محاسـبـ

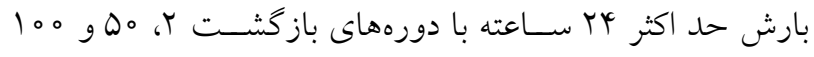

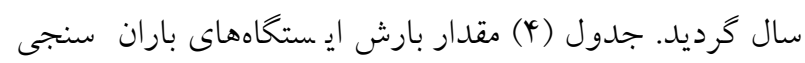
منطقه بهازاى دوره باز خشتهاى مختلف و توزيع آمارى مناسب را نشان مىدهد.

\section{واسنجى و صحتسنجى مدل بارش - رواناب}

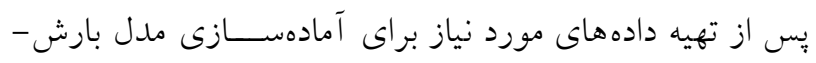

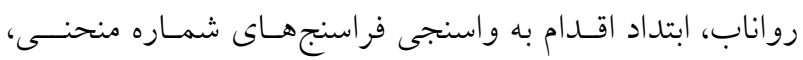

بهطورخلاصــه در اين تحقيق، سـامانهُ اطلاعات جغرافيايى

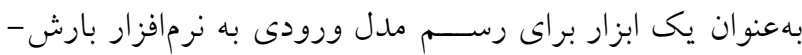

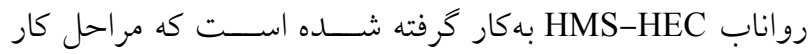
بهشرح زير مىباشد:

\section{مدلهاى مورد استفاده}

Arch- ملهاى مورد استفاده در اين يزوهش بهترتيب مدلهاى Geo-HMS ، Hydro Geo-HMS براى جداسـازى زيرحوضـهها، مدل Arch-Hydro تحت ســامانهُ اطلاعات جغرافيايى براى اسـتخراج لايه ورودى مدل بارش و رواناب به كار رفت. مدل HEC-HMS بهعنوان مدل بارش - رواناب براى شبيهسازى دبى لحظهاى زيرحوضهها براى وقايع مختلف بارش ا ستفاده شد. جدول (Y) مششخصات وقايع ســيلهاى اندازه گيرى و انتخاب شــده براى واســنجى و صحتسنجى مدل HEC-HMS را نشان مىدهد.

$$
\text { سرىهاى زمانى به كاررفته }
$$

اولين اقدام جمع آورى و مرتبســازى ســـىهاى زمانى شـامل آمار بارش حداكثر ب ساعته در ايستخاهاى بارانسنجى داخل و و خارج از منطقه و دبى سـيلاب براى و واقعه سـيل در ايسـتخاه هيدرومترى بارز در خروجى حوضسه بود. وقايع سـيلاب مورد استفاده در جدول (r) خلاصه شده است. 
جدول r. خصوصيات فيزيوگرافيك زيرحوضههاى آبريز رود خانهُ خرسان

\begin{tabular}{|c|c|c|c|c|}
\hline طول آبراهئ اصلى (كيلومتر) & شيب متوسط وزنى حوضه & ارتفاع متوسط وزنى (متر) & (كساحت مترمربع) & نام زيرحوضه \\
\hline YY/DT & $Y I / T Q$ & $|V| \circ / 94$ & $m q / 01$ & SUB I \\
\hline$V Y / M I$ & $Y Q / V$ & T०GY/GT & $\Lambda \mid Y / \Delta \Lambda$ & SUB r \\
\hline$\Delta r / T Q$ & $r q / 4$ & $r Y \circ \Delta / \Delta r$ & Y००/AV & SUB r \\
\hline$\varphi Q / \circ q$ & $r \Delta / I V$ & YIYN/G| & $T V Y / \Lambda$ & SUB ${ }^{r}$ \\
\hline TT/DY & $T Y / \Lambda$ & וTM & $\varphi \circ \mu / 19$ & SUB ه \\
\hline$r Y / \Lambda \mu$ & $19 / 19$ & rIS9/rV & $|\circ \Lambda / \mu|$ & SUB 9 \\
\hline$\Lambda / \mu \Delta$ & IY/r & TYYV/V & IVDV/TY & SUB v \\
\hline$\vee 9 / 1$ & $r Q / G r$ & rOFI/Q & $|V \Delta \circ / N|$ & $\mathrm{SUB} \wedge$ \\
\hline$\Delta V / F Y$ & TI/99 & r $10 / / V 9$ & VQN/Or & SUB 9 \\
\hline$V 4 / 9 V$ & TG/TV & Y190/TY & $\Lambda V Y / q Y^{F}$ & SUB $1 。$ \\
\hline $1 \circ 9 / 91$ & YN/AT & MMYN/A & $1001 / \% q$ & SUB 11 \\
\hline YAT/VY & $r V / A q$ & $r M \circ r / F Y$ & $q \circ r q / 1 T$ & كل حوضه \\
\hline
\end{tabular}

شده است. جدول (r) خصو صيات فيزيو گرافيك زيرحو ضههاى آبريز رودخانه خر سان مستخرج از نرمافزار Geo HMS را ذشان

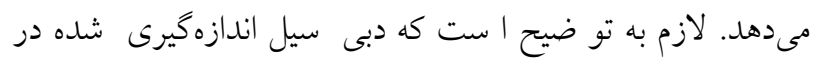
ايستخاه آبســنجى بارز در شـمال شـــقى حوضـهُ آبريز براى واسنجى و صحتسنجى به كار گرفته شده است.

\section{نتايج و بحث}

جدول (Y) توزيعهاى آمارى برازش داده شـــه برروى دادههاى ايستخاههاى بار انسنجى و مقدار ميانخين انحر اف خطاى هر يك از توزيع ها را نشــــان مىدهد. بدينترتئ توزيعى كه مقدار ميانخين انحراف خطاى آن كمتر باشــــ، برازش بهترى با داهها

$$
\text { داشته است. }
$$

از روى توزيعهاى آمارى متناسـب با سـرى دادههاى هر يك از ايســـاه بارانســنجى منطقه مورد مطالعه (جدول \&)، باران با

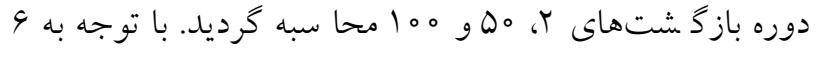
ايستخاه بار ان سنجى مورد برر سى، تعداد 4 عدد براى هر يك از دوره باز گشت ها حاصل شد (جدول ه).
ضرايب ما سكينگام (K و X ) و تلفات اوليه بارش (IIa) براى هر يك از زيرحو ضهها و آبراههها با استفاده از الكوريتم جستجوى نلدرميد گرديد و يس از صحتسنجى آن، مدل براى شبيهسازى به كار كرفته شد. براى واسنجى فراسنجهاى مدل بارش - رواناب

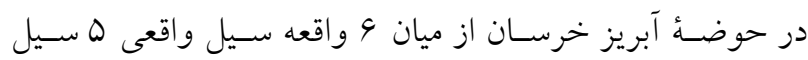
انتخاب كرديد. ه V درصد دادهها براى واسنجى و ها درصد آنها براى صحت سنجى بلهار كرفته شد. اين سيلها در جدول (r) خلاصه شدهاند. براى مقايسه دبى اوج و زمان رسيدن به آن در هيدرو گراف واقعى و محاســبه شــــه، روش مجموع مجذور باقيماندهها، ضريب همبستخى و ريشه ميانخين مجموع مربعات

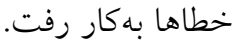

شبيهسازى دبى بيك سيلاب زيرحوضهها يس از تعيين لايئ يا اطلاعات ورودى مدل بارش- رواناب و

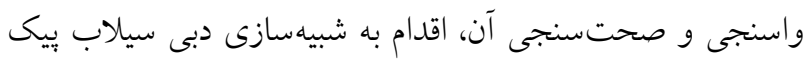
براى و واقعه بارش مندرج در جدول (Y) گرديد. لا ئه ورودى بهد ست آمده براى مدل بارش - رواناب در شكل (Y) ذشان داده 


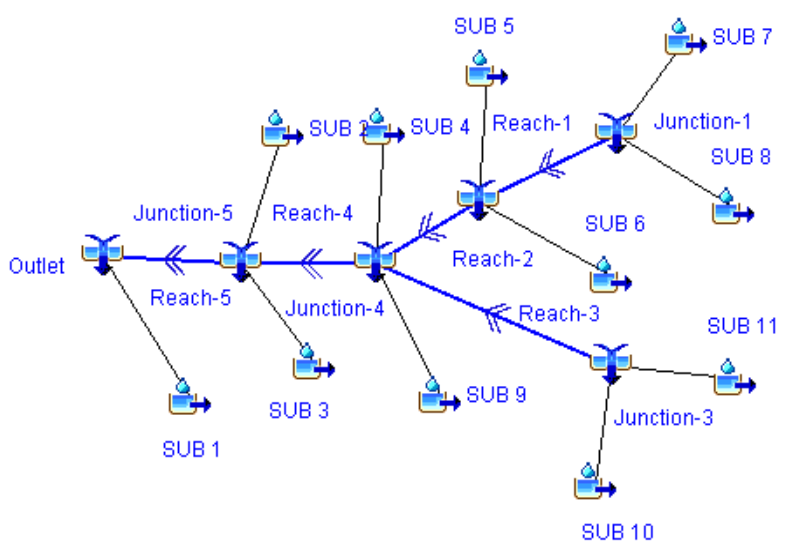

HEC-HMS شكل r. استخراج اطلاعات ورودى براى مدل بارش - رواناب

جدول F. توزيعهاى آمارى سرىهاى حداكثر بارش YF ساعته ايستخاههاى بارانسنجى منطقه مطالعاتى

\begin{tabular}{|c|c|c|c|c|c|c|c|c|}
\hline توزيع مناسب با دادههاى & كامبل & لو تَ ييرسون & تيرسون & دو گِاماى & 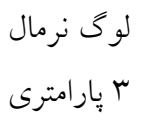 & 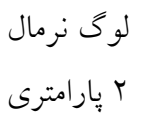 & نرمال & ايستخاه \\
\hline بيرسون تيب ץ & $9 / 11$ & D/T & $r / T$ & $9 / \pi$ & $r / \mu$ & $Q / \circ \psi^{\psi}$ & $\times \wedge / 90$ & آلونى \\
\hline يِيرسون تيب ץ & $Y / T V$ & $r / 4$ & $\varphi / \mu$ & $r / 9 r$ & $Y / 01$ & $4 / 9$ & $\Lambda / \vee \wedge$ & باغ ملك \\
\hline لو بِيرسون تيب ץ & $r / v i$ & $r / 9$ & Y/QT & $r / 99$ & $r / 99$ & $r / v$ & سת/ & 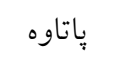 \\
\hline كامبل تيب 1 & $0 / 9$ & $9 / V$ & $19 / \mu \wedge$ & $9 / 0 Y$ & $9 / N$ & $Q / D T$ & $10 / I V$ & حنا \\
\hline لو & $r / V T$ & $r / 19$ & r/^ه & r/gr & $\Delta / 1 T$ & $r / 90$ & $9 / 49$ & ل لردخان \\
\hline لو بِيرسون تيب r & $9 / 99$ & D/A & $I r / r V$ & $9 / 94$ & $V / T V$ & $1 \pi / v \Delta$ & $r Y / I V$ & ياسوج \\
\hline
\end{tabular}

جدول ه. مقدار حداكثر بارش بF ساعته ايستگاههاى بارانسنجى منطقه بهازاى دوره باز گشتهاى مختلف و توزيع آمارى مناسب

\begin{tabular}{|c|c|c|c|c|c|c|c|}
\hline (ميلى متر) & (مهلى ساله & (ميلى متر ) ماله & (ميلى متر ) & (ميلى متر ) & (ميلى متر) & توزيع آمارى مناسب & نام ايستخاه بارانسنجى \\
\hline $94 / 19$ & $\Lambda \uparrow / v q$ & $V I / N{ }^{4}$ & $G Y / \circ D$ & $\Delta T / Y q$ & $r q / q \mu$ & بيرسون تيِّ r & آلونى \\
\hline $99 / \circ 0$ & $\wedge \Delta / \wedge \varphi$ & $V T / D$ & $G Y / Y Q$ & $\Delta T / T \Delta$ & MN/DQ & بيرسون تيِ & باغ ملك \\
\hline $1 / 9 / V Y$ & $1 V r / q$ & $10 r / r q$ & س & $119 / 99$ & $\Lambda \Lambda / \circ \Delta$ & لو گ بيرسون تيبِ r & 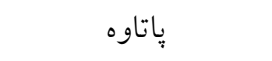 \\
\hline $110 / 4$ & $99 / \circ 9$ & $\Lambda r / q V$ & VT/TY & $90 / 1 \mathrm{~V}$ & FI/Ar & كامبل تي״ 1 & حنا \\
\hline $199 / 4 \mathrm{~V}$ & $101 / 09$ & $1 Y q / \circ r$ & $11 \% / 0$ & $99 / 01$ & $V T / Y V$ & لو گ بيرسون تيب r & ل ل لردگان \\
\hline$|\Psi| / A V$ & $111 / \mathrm{r}$ & $11 / 9 \Lambda$ & $q 4 / 4 q$ & $0 \circ / \Lambda Q$ & TG/Vo & لو گ بيرسون تيب م & ياسوج \\
\hline
\end{tabular}

وقايع سيلابى و بارشهاى متناظر با آنها در جدول (9) نشان مشاهده و محا سبه شده در مرحلة وا سنجى را براى يك واقعه

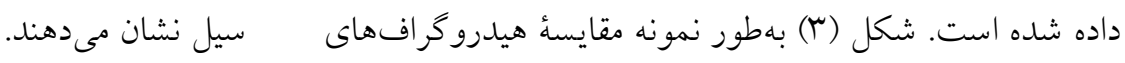


جدول و. وقايع سيلاب و بارشهاى متناظر با آنها براى واسنجى و اعتبار يابى

\begin{tabular}{|c|c|c|c|}
\hline متوسط بارش متناظر سيلابها & (متى اوج سيل & تاريخ وقوع سيلاب & ايستخاه آبسنجى \\
\hline rA & $914 / 41$ & 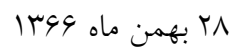 & \multirow{6}{*}{ يستخاه آبسنجى بارز } \\
\hline $10 / 4$ & $9 V / 4$ & rr دی ماه IrV & \\
\hline 19 & $10 \circ / 1$ & 9 بهمن ماه ITVA & \\
\hline$r \mid / 4$ & rrI/D & 19 بهمن ماه |N1r| & \\
\hline rq & $1 \circ \wedge r / 9$ & ه دى ماه سربا & \\
\hline rr & $\varphi \circ r / V$ & צr آبان ماه & \\
\hline
\end{tabular}

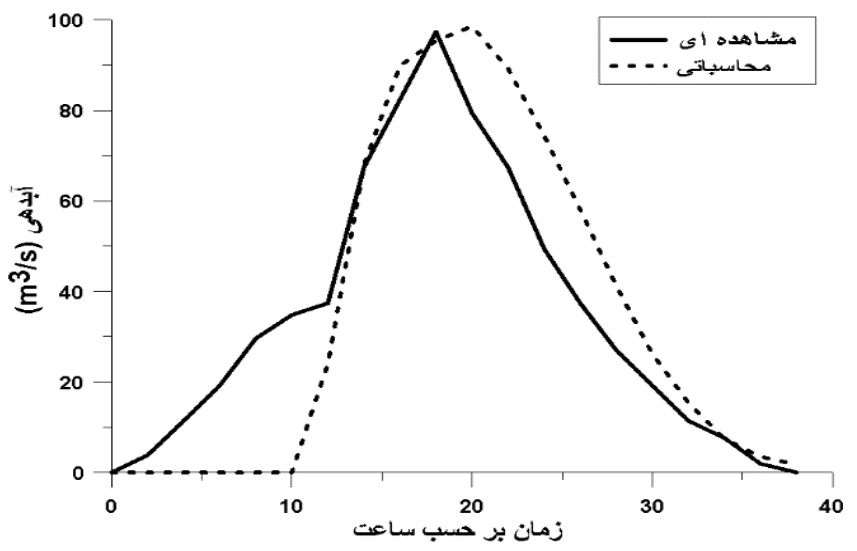

شكل r. هيدروگر افهاى مشاهدهاى و شبيهسازى شده سيل س ب دى ماه IrV9 در مرحله واسنجى

جدول V. نتايج آبنغار واقعى و شبيهسازى شده يس از واسنجى

\begin{tabular}{|c|c|c|c|c|c|}
\hline RMSE & SSR & $\mathrm{R}^{r}$ & $\begin{array}{c}\mathrm{Qp}_{\mathrm{p}} \\
\mathrm{m}^{\mathrm{r}} / \mathrm{s}\end{array}$ & $\begin{array}{c}\mathrm{Qp}_{\mathrm{p}} \\
\mathrm{m}^{\mathrm{r}} / \mathrm{s}\end{array}$ & وقوع سيلاب \\
\hline $10 / \wedge r$ & 。 & $0 / 911$ & $91 / 9$ & $q V / 4$ & سT دى ماه ITVG \\
\hline$r q / 19$ & $M 1 / 9$ & $\circ / \Lambda \Delta V$ & $109 / \mathrm{V}$ & $100 / 1$ & 9 بهمن ماه IrVA \\
\hline $10 / 7 q$ & 。 &.$/ \mathrm{V} 19$ & $r \mid r / 9$ & MTI/D & | 19 بهمن ماه |r|r| \\
\hline Gr/Ar & 。 & - ard & $Y \backslash \Lambda / \Lambda$ & $r \circ r / v$ & 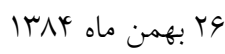 \\
\hline $\mid \Lambda Y / M$ & $\mid \& N / 9$ & O/grt & $119 \mathrm{~V} / \mathrm{V}$ & $10 \wedge r / 9$ & ه دى ماه سرب| \\
\hline
\end{tabular}

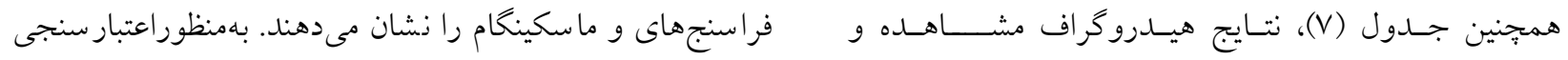

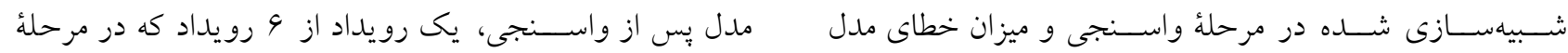
شبيهسازى شده را نشان مىدهد. نتايج حاكى از دقت بالاى مدل واسنجى مورد استفاده قرار نخرفته بود، انتخاب شد. اين رويداد

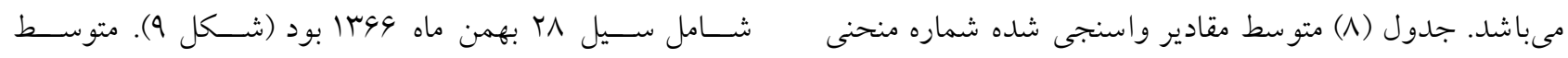
و تلفات اوليه و جدول (9) نتايح متوســط مقادير واســنجى فراسنجهاى بهدست آمده از الكوريتم Nelder-Mead در مرحلة 


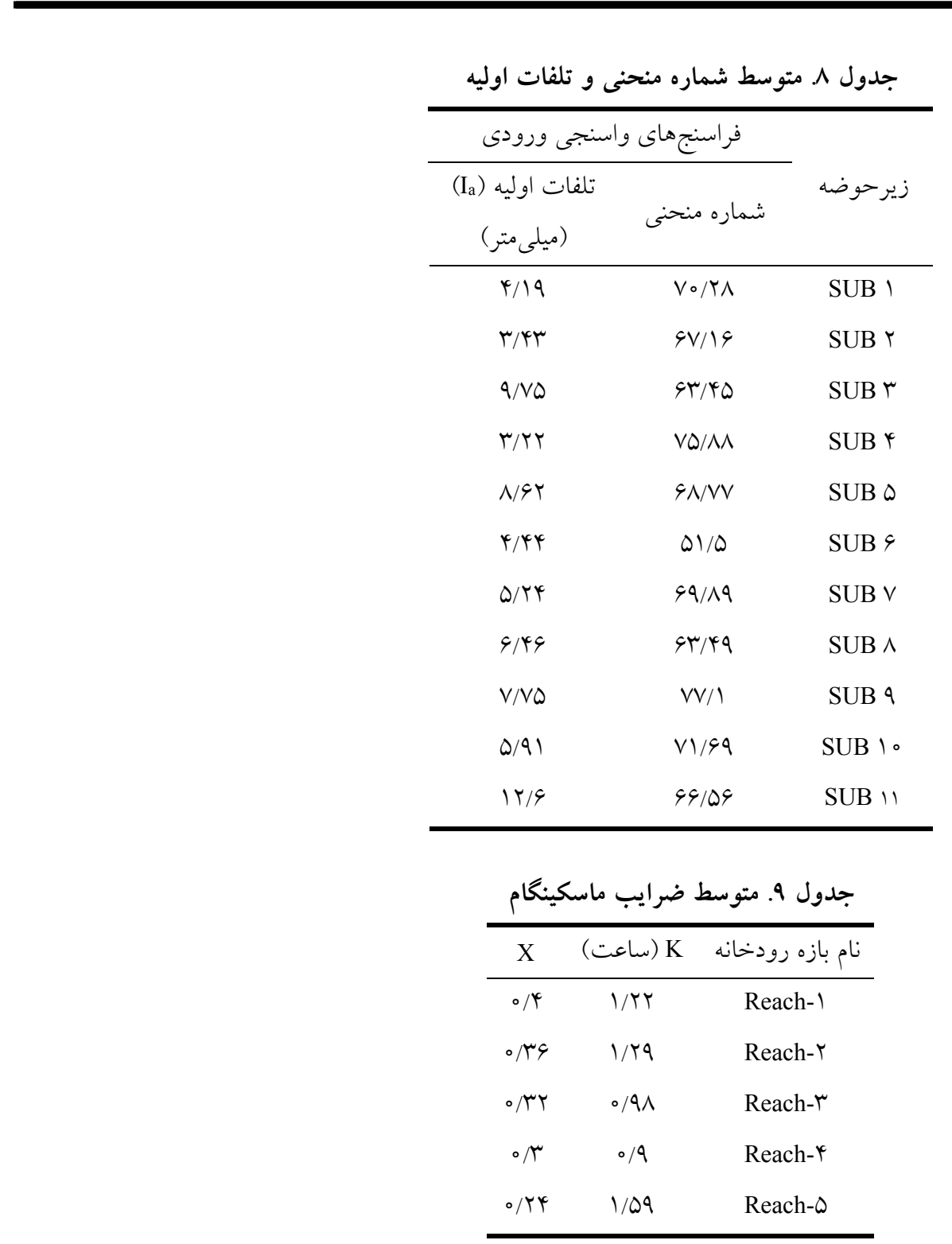

جدول • ا. مقايسهُ نتايج هيدروگراف مشاهد و محاسبه شده در مرحلهُ اعتبارسنجى

\begin{tabular}{|c|c|}
\hline TA بهمن ماه Y49 & مورد \\
\hline $91 \% / Y \wedge \mathrm{m}^{r} / \mathrm{s}$ & مشاهده Qp \\
\hline $990 / 1 \mathrm{~m}^{r} / \mathrm{s}$ & Q شبيهسازى Qp \\
\hline - gaty & $\mathrm{R}^{r}$ \\
\hline $9 / 94$ & درصد خطا \\
\hline IY/MT & RMSE \\
\hline
\end{tabular}

واسـنجى به مدل داده شـد كه نتايج اعتبارسـنجى مدل بارش - نمونه در جدول (11) ارائه شــده اســت. براســاس اين جدول

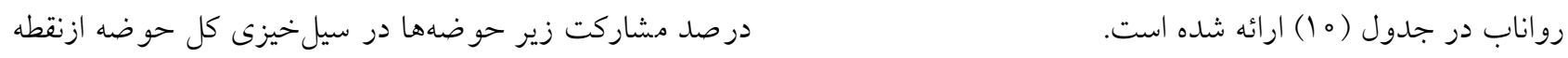
جزئيات اولويتبندى براى دوره بازگشـت مها سـال بهطور نظر مساحت و دبى زيرحوضهها با هم متفاوت مىباشد. 


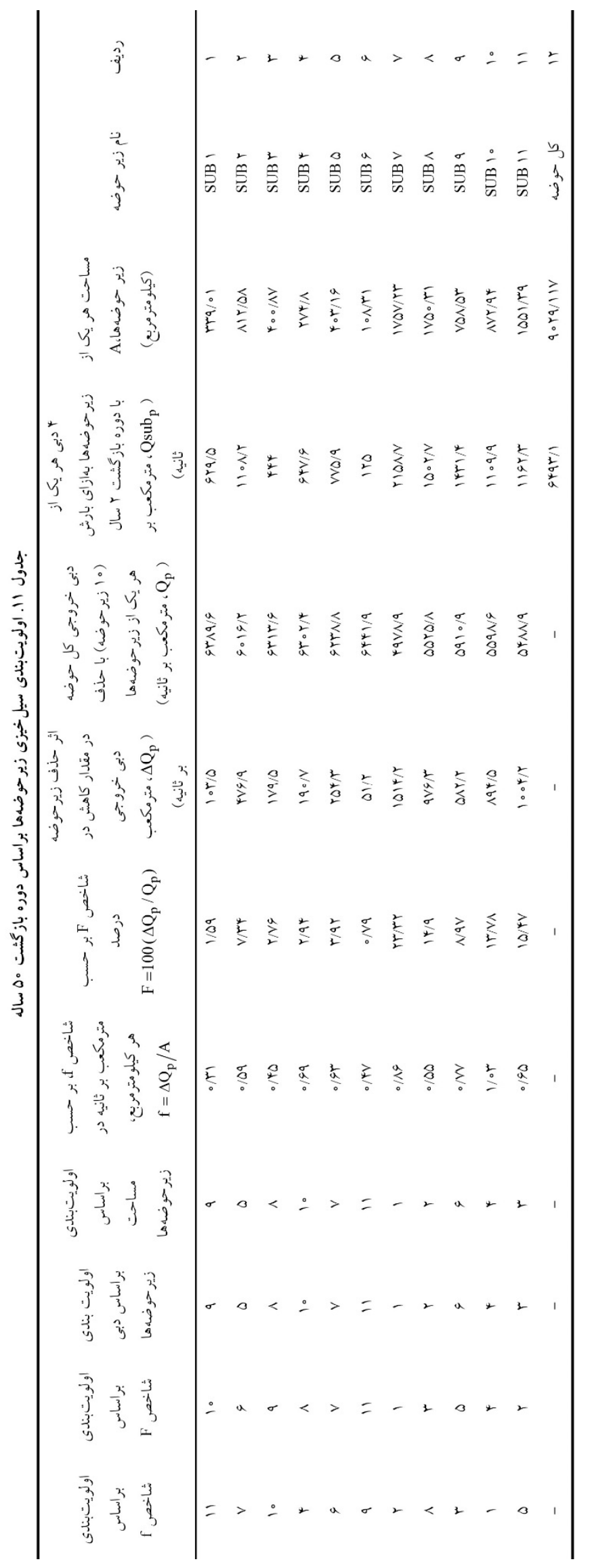




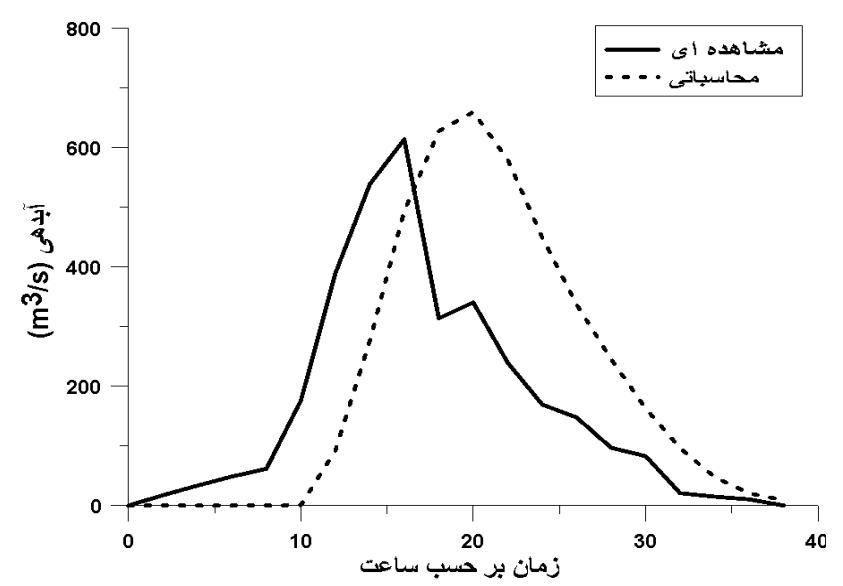

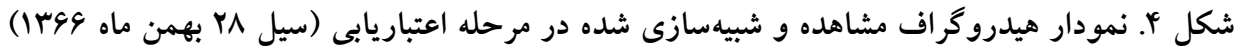

در سيل خروجى كل حوضه تأثير بيشترى ندارد.

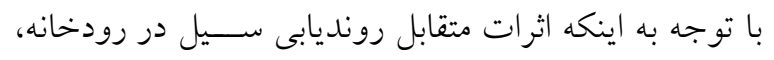

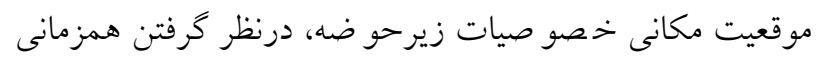

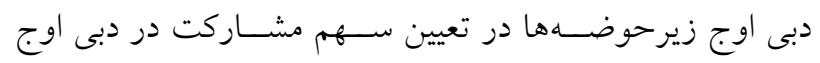

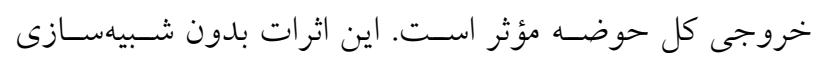

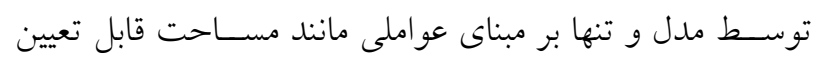
نمىباشند. اولويتبندى زيرحوضسهها در ســيل خروجى حوضسـه در

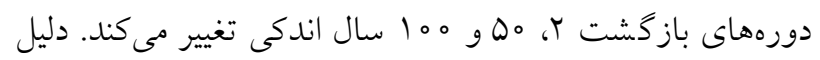

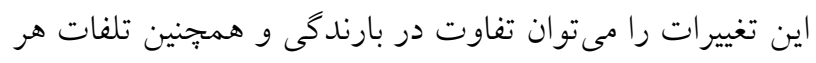

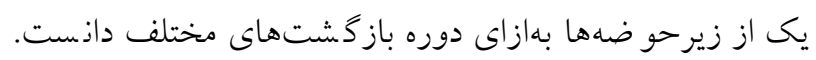

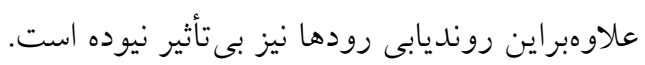

\section{بيشنهادات}

با توجه به تأثير بيشـتر حوضسههاى ميانى در سـيل خيزى كل

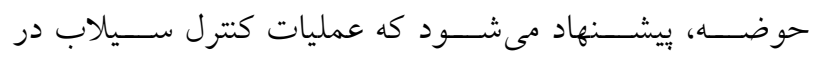
زيرحوضههاى ميانى متمركز شود و اولويت با اين زير حوضهها

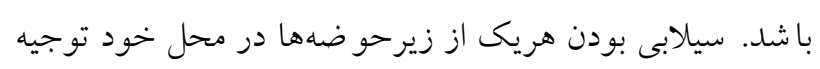

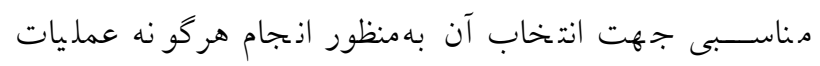

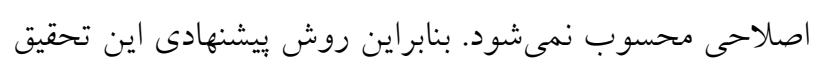

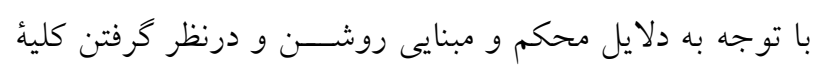

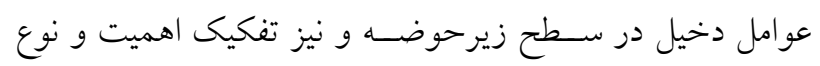

طبق جدول (Y I)، دليل تغييرات دبى زير حوضسهها را مىتوان به

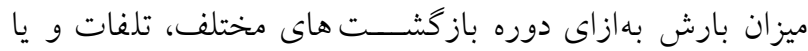

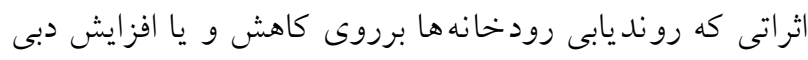

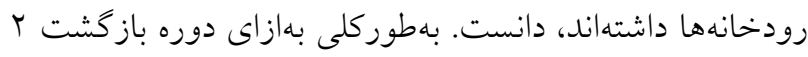

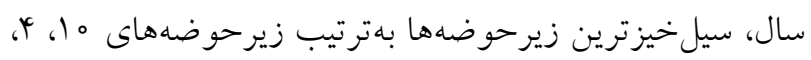

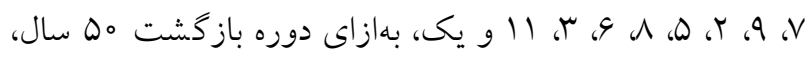

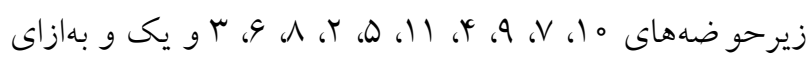

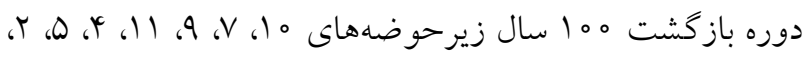
^، 9، ب و يكى سيل خيزترين زيرحوضهها مى باشند.

\section{نتيجه گيرى}

با تلفيق ســامانه اطلاعات جغر افيايى و مدلهاى هيدرولوزيكى دئى

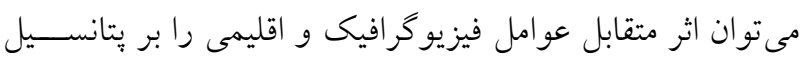

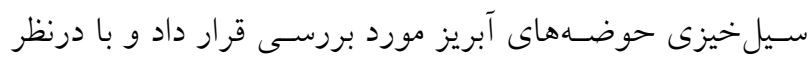

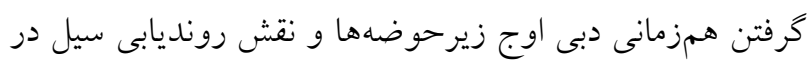

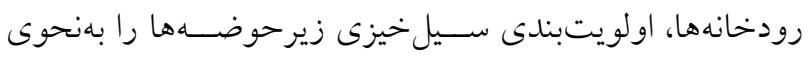

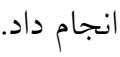
زمانى كه ميزان تأثير دبى زيرحوضــهـها بِ إس از حذف در

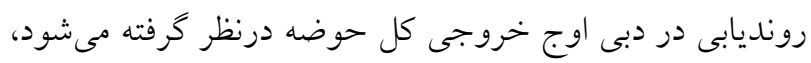

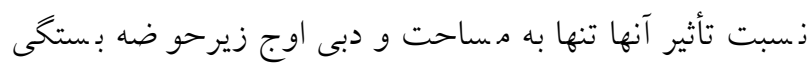

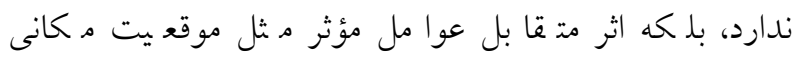
زير حوضـهها مى تواند نقش مهمى داثـته باشــــ بنابر اين لزوماً

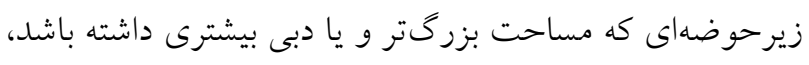




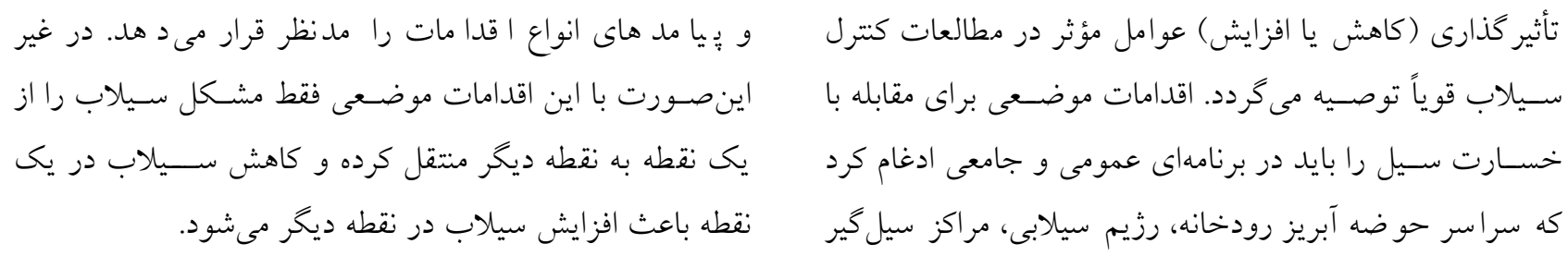

منابع مورد استفاده

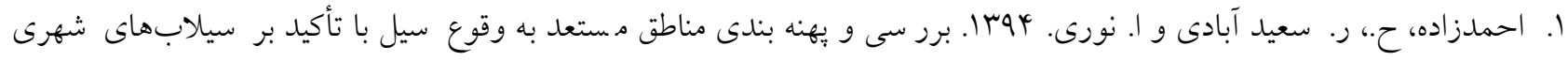

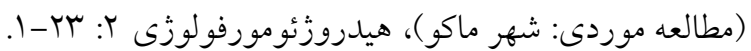

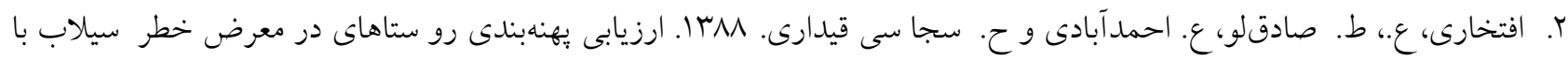

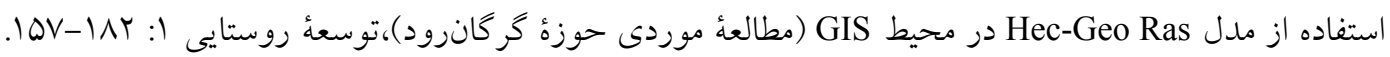

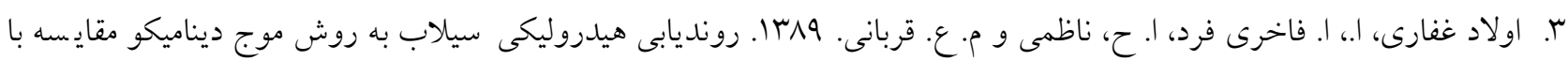

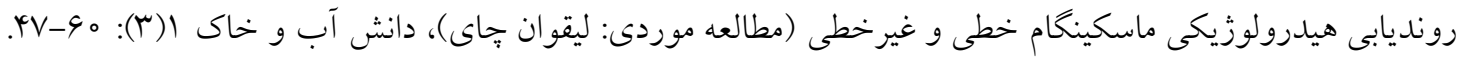

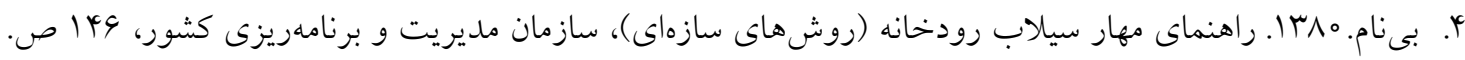

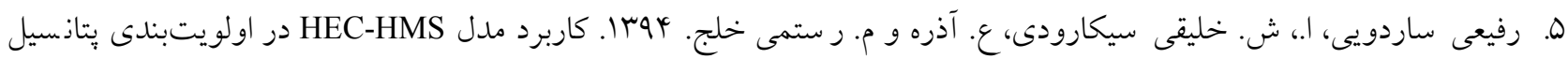

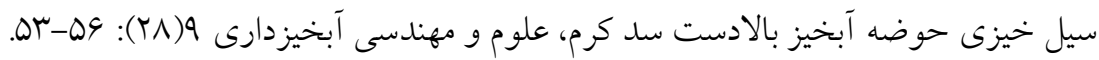

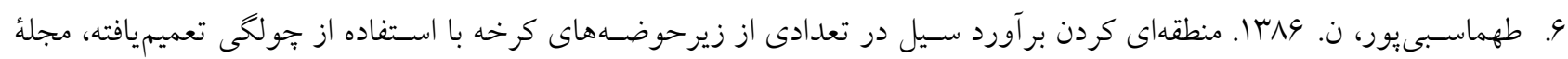

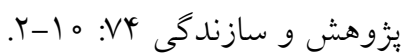

V. ميرناصـرى، م و ر. فضــل اولى. اوجا. بهنهبندى سـيلاب با تلفيق نرمافزارهاى HEC-RAS و GIS (مطالعه موردى: بخشسى از

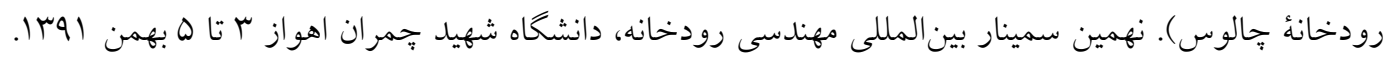

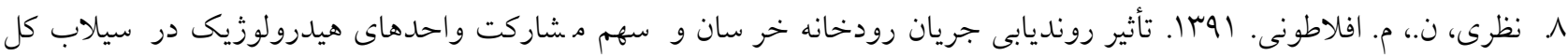

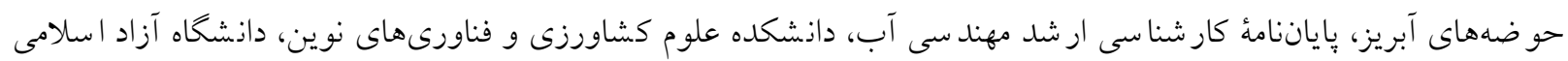
شيراز.

9. Chow, V. T., D. R, Maidment and L. W. Mays. 1956. Applied Hydrology. PP: 122-126. In: Mc Graw-Hill International Editions, Civil Engineering Series.

10. Choudhari, K., B. Panigrahi and J. C. Paul. 2014. Simulation of rainfall-runoff process using HEC-HMS model forBalijore Nala watershed, Odisha, India, J. Geomathics and Geosciences 5(2): 253-266.

11. Heghedus, P., S. Czigany, L. Balatonyi and E. Pirkhoffer. 2013. Sensitivity of the HEC-HMS runoff model for earsurface soil moisture contents on the example of a rapid- response catchment in SW Hungary, J. Riscuri Si Catastrofe 12(1):125-137.

12. Kumar, D and R. K. Bhattacharjya. 2011. Distributed Rainfall Runoff Modeling, J. Earth Sci. and Eng. 4(6): 270-275.

13. Noman N. S., E. J. Nelson and K. A, Zundel. 2001. Review of Automated Floodplain Delineation from Digital Terrain models. J. Water Resources Planning and Management. 6: 394-402.

14. Parker, D. J. 2002.Floods. PP: 22-23. In: London and New York Ltd.

15. Smith, P. 1997. Hydrologic data development system. J. Transportation Res. Board 5(4): 118-127.

16. Ward, R. C. 1978. Floods- A Geographical Perspective. PP: 55-58. In: London, Macmillan Press Ltd. 


\title{
Determination of Sub-Basins Flow Contribution to Total Flood in Khersan River Basin
}

\author{
N. Tavanpour ${ }^{1^{*}}$, M. Aflatooni ${ }^{2}$ and N. Nazari ${ }^{2}$
}

(Received: Feb. 2-2016 ; Accepted: June 11-2016)

DOI: 10.18869 /acadpub.jstnar.20.78.77

\begin{abstract}
This research is aimed to determine the contribution of sub-basins flow to total watershed flood in Khersan river basin located in Kohkilooyeh and Boyer Ahmad province. To do this, the rainfall-runoff model HEC-HMS was used to simulate peak runoff values for 11 sub-basins. HEC-HMS input was constructed using GIS. The results suggest that the change in different return periods is accompanied by small change in prioritization of flood-potential of the sub-basins; so that for return periods of 2, 50 and 100 years, the most contributions came from sub-basins 1 through 11, respectively. With respect to area and flow rate, contribution of sub-basins to watershed total flow was different. The effect of area was between 0.31 to 1.03 percent; namely, sub-basin 6 showed the highest rank and basin 7 showed the lowest one. With respect to peak flow rate, the effect of individual exclusion of sub-basins, resulted in contribution between 51.2 to 1004.2 $\mathrm{m}^{3} / \mathrm{s}$, that is, sub-basin 6 showed the lowest effect and the sub basin 11 showed the highest contribution.
\end{abstract}

Keywords: flood potential; geographic information system; Khersan river basin; rainfall-runoff model

1. Dept. of Water Eng., Faculty of Agric., Shiraz Univ., Shiraz, Iran.

2. Dept. of Water Sci. College of Sci., Agric. and Innovative Tech., Islamic Azad Univ., Shiraz, Iran.

*: Corresponding Author, Email: nima.tavanpour@gmail.com 